\title{
Introgressive hybridization in a Spiny-Tailed Iguana, Ctenosaura pectinata, and its implications for taxonomy and conservation
}

\author{
Eugenia Zarza ${ }^{\text {Corresp., } 1,2,3}$, Victor H Reynoso ${ }^{\text {Corresp., } 1}{ }^{,}$, Christiana M A Faria ${ }^{4}$, Brent C Emerson ${ }^{5}$ \\ ${ }^{1}$ Departamento de Zoología, Instituto de Biología, Universidad Nacional Autónoma de México, Ciudad de México, Mexico \\ 2 Grupo Académico de Biotecnología Ambiental, El Colegio de la Frontera Sur, Unidad Tapachula, Tapachula, Chiapas, Mexico \\ ${ }^{3}$ CONACYT, Ciudad de México, Mexico \\ 4 School of Biological Sciences, University of East Anglia, Norwich, United Kingdom \\ 5 Island Ecology and Evolution Research Group, Instituto de Productos Naturales y Agrobiología (IPNA-CSIC), C/Astrofísico Francisco Sánchez 3, La Laguna, \\ Tenerife, Canary Islands, Spain \\ Corresponding Authors: Eugenia Zarza, Victor H Reynoso \\ Email address: eugenia.zarza@gmail.com,vreynoso@ib.unam.mx
}

Introgression, the transmission of genetic material of one taxon into another through hybridization, can have various evolutionary outcomes. Previous studies have detected signs of introgression between western populations of the Mexican endemic and threatened spiny-tailed iguana, Ctenosaura pectinata. However, the extent of this phenomenon along the geographic distribution of the species is unknown. Here we use multilocus data together with detailed geographic sampling to (1) define genotypic clusters within C. pectinata; (2) evaluate geographic concordance between maternally and biparentally inherited markers; (3) examine levels of introgression between genotypic clusters, and (4) suggest taxonomic modifications in light of this information. Applying clustering methods to genotypes of 341 individuals from 49 localities of $C$. pectinata and the closely related $C$. acanthura, we inferred the existence of five genotypic clusters. Contact zones between genotypic clusters with signatures of interbreeding were detected, showing different levels of geographic discordance with mtDNA lineages. In northern localities, mtDNA and microsatellites exhibit concordant distributions, supporting the resurrection of $C$. brachylopha. Similar concordance is observed along the distribution of $C$. acanthura, confirming its unique taxonomic identity. Genetic and geographic concordance is also observed for populations within southwestern Mexico, where the recognition of a new species awaits in depth taxonomic revision. Contrarily, in western localities a striking pattern of discordance was detected where up to six mtDNA lineages co-occur with only two genotypic clusters. Given that the type specimen originated from this area, we suggest that individuals from western Mexico keep the name $C$. pectinata. Our results have profound implications for conservation, management, and forensics of Mexican 
iguanas. 


\section{Introgressive Hybridization in a Spiny-Tailed Iguana,}

\section{Ctenosaura pectinata, and its Implications for}

\section{Taxonomy and Conservation.}

4 Short title: Introgression in Ctenosaura pectinata

5

6 Eugenia Zarza ${ }^{1,2,3}$, Víctor H. Reynoso ${ }^{1}$, Christiana M.A. Faria ${ }^{4 \# a}$ and Brent C. Emerson ${ }^{5}$

$7{ }^{1}$ Departamento de Zoología, Instituto de Biología, Universidad Nacional Autónoma de México,

8 Ciudad de México, Mexico

$9{ }^{2}$ Grupo Académico de Biotecnología Ambiental, El Colegio de la Frontera Sur, Unidad

10 Tapachula, Tapachula, Chiapas, Mexico

$11{ }^{3}$ CONACYT, Ciudad de México, Mexico.

$12{ }^{4}$ School of Biological Sciences, University of East Anglia, Norwich, United Kingdom

$13{ }^{5}$ Island Ecology and Evolution Research Group, Instituto de Productos Naturales y Agrobiología

14 (IPNA-CSIC), C/Astrofísico Francisco Sánchez 3, La Laguna, Tenerife, Canary Islands, 38206,

15 Spain

16 Corresponding authors:

17 Eugenia Zarza

18 Email address: eugenia.zarza@gmail.com

19 Víctor H. Reynoso

20 Email address: vreynoso@ib.unam.mx 
22 \#a Current Address: Departamento de Biologia, Universidade Federal do Ceará, Campus do Pici, 23 Bloco 906, Fortaleza, Ceará, CEP 60455-760, Brasil 


\section{Abstract}

25

26

27

Introgression, the transmission of genetic material of one taxon into another through hybridization, can have various evolutionary outcomes. Previous studies have detected signs of introgression between western populations of the Mexican endemic and threatened spiny-tailed iguana, Ctenosaura pectinata. However, the extent of this phenomenon along the geographic distribution of the species is unknown. Here we use multilocus data together with detailed geographic sampling to (1) define genotypic clusters within C. pectinata; (2) evaluate geographic concordance between maternally and biparentally inherited markers; (3) examine levels of introgression between genotypic clusters, and (4) suggest taxonomic modifications in light of this information. Applying clustering methods to genotypes of 341 individuals from 49 localities of $C$. pectinata and the closely related C. acanthura, we inferred the existence of five genotypic clusters. Contact zones between genotypic clusters with signatures of interbreeding were detected, showing different levels of geographic discordance with mtDNA lineages. In northern localities, mtDNA and microsatellites exhibit concordant distributions, supporting the resurrection of $C$. brachylopha. Similar concordance is observed along the distribution of $C$. acanthura, confirming its unique taxonomic identity. Genetic and geographic concordance is also observed for populations within southwestern Mexico, where the recognition of a new species awaits in-depth taxonomic revision. Contrarily, in western localities a striking pattern of discordance was detected where up to six mtDNA lineages co-occur with only two genotypic clusters. Given that the type specimen originated from this area, we suggest that individuals from western Mexico keep the name C. pectinata. Our results have profound implications for conservation, management, and forensics of Mexican iguanas. 


\section{Introduction}

The role of introgression, or gene flow between divergent lineages (Streicher et al., 2014;

Haenel, 2017; Kumar et al., 2017; Pilot et al., 2018) in shaping biodiversity is receiving increasing attention in different taxa and geographic areas (e.g. Abbott et al., 2013; Haus, Roos \& Zinner, 2013; Mallet, Besansky \& Hahn, 2016). There is evidence suggesting that introgression can increase the risk of extinction in endangered species through genetic swamping (Frankham, 2006). Additionally, introgression can have deleterious effects in hybrids, lead to adaptation by the emergence of novel genotypes, or have no effect on the fate of a species (Seehausen, 2004; Mallet, 2005; Frankham, 2006; Kronforst, 2012; Pardo-Diaz et al., 2012). Given these various outcomes, it is particularly important to study the extent and impact of introgression in biologically rich areas like Mesoamerica, where general patterns of genetic diversity are just starting to be uncovered (Ornelas et al., 2013; Mastretta-Yanes et al., 2015; Nieto-Montes de Oca et al., 2017; Bryson et al., 2017; Rodríguez-Gómez \& Ornelas, 2018). The results of such studies can have direct implications for species delimitation and, ultimately, conservation and wildlife management (Gompert, 2012). Hot Spot (Myers et al., 2000). Many phylogeographic studies have focused on this area, though only a few of them have employed a multilocus approach that can detect the presence of introgression (e.g. Daza et al., 2009; Greenbaum, Smith \& de Sá, 2011; Pringle et al., 2012; Arbeláez-Cortés, Milá \& Navarro-Sigüenza, 2014; Arbeláez-Cortés, Roldán-Piña \& NavarroSigüenza, 2014). In the spiny-tailed iguana Ctenosaura pectinata, distributed in the lowlands of the Pacific slope and the Balsas Depression in Mexico (Smith \& Taylor, 1950; Köhler, Schroth 
$70 \&$ Streit, 2000), initial phylogeographic studies recovered eight mitochondrial DNA (mtDNA)

71 lineages, recognized as statistically supported nodes in a phylogeny: North A, North B, North C,

72 Colima, Balsas, Guerrero, Oaxaca and South (Fig. 1, Fig. S1; Zarza, Reynoso \& Emerson, 2008).

73 Ctenosaura acanthura, found in the lowlands of the Gulf of Mexico, appeared as sister to the

74 South lineage, whereas $C$. hemilopha and $C$. similis were recovered as clearly distinct lineages

75 (Zarza, Reynoso \& Emerson, 2008).

76

Genetic distances (Tamura \& Nei, 1993) between C. pectinata mtDNA lineages range

77 from 4.11 to $11.57 \%$, similar to values estimated among species of iguanas of the genus Cyclura

78 (Malone et al., 2000). The North and Colima mtDNA lineages show the largest distance

79 measured within C. pectinata (Zarza, Reynoso \& Emerson, 2008). This phylogeographic break

80 occurs in the vicinity of the Trans-Mexican Volcanic Belt (TMVB; Fig. 1), on the central

81 western coast of Mexico and, probably occurred between 1.1 and 3.1 million years ago (Zarza,

82 Reynoso \& Emerson, 2008). This geological feature, a volcanic belt that covers central-southern

83 Mexico from the Pacific Ocean to the Gulf of Mexico, has attracted many biogeographers

84 because this represents the distributional limits of highland and lowland taxa (e.g. Mastretta-

85 Yanes et al., 2015; Zaldivar-Riverón, Leon-Regagnon \& de Oca, 2004; Devitt, 2006; Mulcahy,

86 Morrill \& Mendelson, 2006; Bryson, García-Vázquez \& Riddle, 2012; Blair et al., 2015).

87 Additional multilocus data and detailed geographic sampling of $C$. pectinata in this area revealed

88 a ninth mtDNA lineage occurring between North C and Colima lineages: North D (Zarza,

89 Reynoso \& Emerson, 2011; Fig. 1). Interestingly, the North C, North D, Colima and Balsas

90 mtDNA lineages show geographically discordant patterns with two clusters identified with

91 microsatellite markers (Zarza, Reynoso \& Emerson, 2011). The discordance likely resulted from

92 contemporary and/or past introgression among lineages, coupled with male sex biased dispersal 
93 (Zarza, Reynoso \& Emerson, 2011). It is unknown if geographic discordance between mtDNA

94 and microsatellite markers, and introgression are restricted to this part of C. pectinata

95 distribution, or if it is prevalent among other neighboring populations.

96 These previous molecular studies in Ctenosaura pectinata have uncovered diversity that

97 had been overlooked or not detected by the most recent morphological revisions of the species

98 and closely related taxa (Köhler, Schroth \& Streit, 2000; Köhler, 2002). This is in contrast to

99 earlier studies of the genus. Ctenosaura pectinata was described by Wiegman (1834). Bailey

100 (1928), in a revision of the genus recognized five species (C. brachylopha, C. pectinata, $C$.

101 acanthura, C. brevirostris, $C$. parkeri) within the range of what we currently know as $C$.

102 pectinata. He stated that $C$. acanthura was the most widely distributed, inhabiting both the

103 western and eastern coasts of Mexico. He indicated that C. pectinata and C. brevirostris had

104 approximately the same distribution on the western foothills of Mexico, with 'Colima' as type

105 locality. Ctenosaura parkeri was only known from two collecting sites in Jalisco and Nayarit.

106 Ctenosaura brachylopha was described as inhabiting the northern states of Nayarit and Sinaloa.

107 Without giving any justification, Smith and Taylor (1950) lumped C. brachylopha, C.

108 brevirostris and C. parkeri with C. pectinata and restricted the name C. acanthura for iguanas

109 from the Gulf of Mexico area.

110 In light of recent molecular studies and previous morphological classifications, revisiting

111 C. pectinata genetic diversity and taxonomy is warranted. Taxonomic modifications should rely

112 on morphological information, a multilocus approach, and comprehensive geographic sampling

113 (Leaché \& Fujita, 2010; Bauer et al., 2011; Rittmeyer \& Austin, 2012). A multilocus approach

114 facilitates the identification of genotypic clusters: groups of individuals that have few or no

115 intermediates when in contact (Mallet, 1995). Such groups may inter-grade freely at their 
116 boundaries, but be strongly differentiated and relatively conserved in morphology, genetics and

117 ecology. This implies that species can be affected by gene flow, selection and history, but they

118 are not necessarily defined by these processes (Mallet, 1995). Defining genotypic clusters is

119 useful in cases where gene flow between otherwise differentiated clusters occurs, for example in 120 contact zones, as might be the case of C. pectinata.

121 Here we use multilocus data from individuals sampled across the ranges of Ctenosaura

122 pectinata and the closely related C. acanthura. Our specific aims are to: (1) define genotypic

123 clusters; (2) investigate the levels of geographic concordance between mtDNA lineages and

124 genotypic clusters; (3) evaluate evidence for introgression between clusters; and (4) re-define

125 taxonomic entities based on maternally and biparentally inherited markers, and compare these to

126 previous taxonomic hypothesis.

127

128 Materials and Methods

\section{Sampling and Laboratory procedures}

Spiny-tailed iguanas were collected between 2004 and 2006 using tomahawk traps,

132 noosing, or by hand within the recognized distribution of Ctenosaura pectinata and $C$.

133 acanthura. The narrow area of sympatry between C. pectinata and C. hemilopha in northern

134 Mexico was excluded to avoid the inclusion of $C$. hemilopha alleles in the analyses (Zarza

135 Franco, 2008; Fig. 1). All samples have been analyzed in previous studies (Faria, 2008; Zarza,

136 Reynoso \& Emerson, 2008; Zarza Franco, 2008; Faria et al., 2010; Zarza, Reynoso \& Emerson,

1372011,2016 ) to obtain microsatellite and/or mtDNA data (see File S1 for details). However, all

138 these genetic data have not been analyzed together. All data is available from GenBank (File S1) 
139 or as supplementary material in Zarza et al. (2016), including two previously unpublished

140 mtDNA sequences (GenBank accession numbers KT003209- KT003210), and microsatellite

141 data (File S1) from three localities in northern Mexico (Fig. 1, sites 1-3).

142 We generated datasets for both type of markers that are mostly overlapping regarding

143 sample content (microsatellite $n=341$, mtDNA $n=344$ ) with 317 individuals out of 368 ,

144 represented in both datasets. This study comprises samples from 53 out of 67 localities sampled

145 in the above-mentioned studies; individuals from 49 localities were included in the microsatellite

146 dataset. In some instances, individuals failed to amplify for mtDNA in earlier studies, but were

147 successfully genotyped (24 out 341 samples; File S1). All mtDNA lineages described in previous

148 publications were represented in the mtDNA dataset analyzed herein.

149 A thorough description of the sampling and laboratory methods can be found in (Zarza,

150 Reynoso \& Emerson, 2008; Faria et al., 2010; Zarza, Reynoso \& Emerson, 2011, 2016);

151 however a summarized version follows. From each individual, a tail clip, or a $0.15 \mu 1$ blood

152 sample from the caudal vein were taken and preserved in ethanol. DNA samples were purified

153 using a modified salt precipitation protocol (Aljanabi \& Martinez, 1997). A 561 bp fragment of

154 the mitochondrial NADH dehydrogenase, subunit 4 (ND4) gene was amplified via polymerase

155 chain reaction (PCR) and sequenced using primers ND4, ND4Rev (Arèvalo, Davis \& Sites,

156 1994), ND4F1 (Zarza, Reynoso \& Emerson, 2008) and ND4R623 (Hasbún et al., 2005) with

157 conditions described by Zarza, Reynoso \& Emerson (2008). Individuals were genotyped with

158 nine microsatellite markers. Loci Cthe12, Cthe37 (Blázquez, Rodríguez Estrella \& Munguía

159 Vega, 2006), Pec01, Pec03, Pec16, Pec20, Pec25, Pec73, and Pec89 (Zarza et al., 2009), were

160 PCR amplified using conditions described by Zarza et al. (2011) and run in two multiplexes that

161 allow for loci separation by color and size in an automated ABI PRISM® 3730 (Applied 
162 Biosystems, Foster City, CA, USA). Fragment size was visualized with the GeneMapper

163 software version 4.0 (Applied Biosystems, Foster City, CA, USA).

164 The School of Biological Sciences Ethical Review Committee at the University of East

165 Anglia approved this study as stated in an "Approval letter" to EZ. All efforts were made to

166 minimize stress when taking blood samples, which were obtained under the permits

167 SEMARNAT SGPA/DGVS/08239, SGPA/DGVS/ 02934/06, 03563/06 to VHR.

168

169 Data Analyses

170 Mitochondrial DNA data

171 A median joining haplotype network was calculated with Network (Bandelt, Forster \& Rohl,

172 1999) to update previously proposed haplotype networks (Zarza, Reynoso \& Emerson, 2008,

173 2011). SAMOVA 2.0 (Dupanloup, Schneider \& Excoffier, 2002) was used to define groups of

174 populations that are geographically homogeneous and maximally differentiated from each other

175 and to estimate their hierarchical differentiation. One hundred initial independent processes were

176 tested followed by 10,000 steps of the simulated annealing process, which maximizes the

177 proportion of total genetic variance among groups. Previous studies, uncovered nine mtDNA

178 clades (Zarza, Reynoso \& Emerson, 2008, 2011). To test this grouping pattern and to explore if a

179 larger number of groups existed, SAMOVA analyses were run under scenarios of 2 to 15 groups

180 (K) without geographic restrictions. No coherent geographic structure was detected at $\mathrm{K}=15$, thus

181 higher values of $\mathrm{K}$ were not tested. The $F_{C T}$ index (proportion of total genetic variance due to

182 differences between groups of populations) was used to select the best grouping, i.e. the most

183 suitable K. This index reflects the among-group component of the overall genetic variance. We

184 selected the number of groupings that maximizes this component, meaning that under that 
185 scenario the groups of populations are maximally differentiated from each other (Dupanloup,

186 Schneider \& Excoffier, 2002). To accomplish this, the most suitable K value was selected based

187 on the observed changes of $F_{C T}$ among consecutive $\mathrm{K}$ values. We considered arbitrarily that the

188 most suitable value of $\mathrm{K}$ is observed when there is a $F_{C T}$ change $<1 \%$ between two consecutive

189 Ks. We refer to this as $\Delta F_{C T}$ obtained as $F_{C T K+1}-F_{C T K}$, reflecting changes in the percentage of

190 variation explained by $F_{C T}$. Bar plots were created with R 2.15 (R Core Team, 2012) to show the

191 mtDNA lineage of each individual as determined by the haplotype network (Fig. S1), and to

192 illustrate the results of SAMOVA.

193

\section{Microsatellite data}

195 The software GENEPOP 4.1 (Rousset, 2008) was used to estimate allele and null allele

196 frequencies, to perform tests for linkage disequilibrium between pairs of loci and to detect

197 deviations from Hardy-Weinberg equilibrium. $F_{S T}$ values between localities were calculated with

198 Arlequin 3.5 with the pairwise differences distance method (Excoffier \& Lischer, 2010).

199 The possible number of genotypic clusters under a scenario of admixture was inferred

200 with STRUCTURE 2.3.2 (Pritchard, Stephens \& Donnelly, 2000). Simulations were run

201 assigning a uniform prior for the parameter Alpha (degree of admixture) and estimating the allele

202 frequency parameter (Lambda) assuming correlated allele frequencies. Previous studies in

203 Ctenosaura pectinata showed that a K > 10 was unlikely (Zarza, Reynoso \& Emerson, 2016),

204 thus we limited our STRUCTURE analyses to $K=2-K=10$, with ten iterations for each value

205 and ten million MCMC replicates after a burn-in period of 1,000,000. The most likely number of

206 clusters was inferred with the method of Evanno et al. (2005) implemented in Structure

207 Harvester (Earl \& vonHoldt, 2012). 

same parameters and criteria that were used in the mtDNA analyses, to keep settings uniform across datasets. Bar plots were created with R to show STRUCTURE and SAMOVA results for

211 each individual. The resulting SAMOVA groupings were used to calculate several population 212 metrics as described in the following. Expected and observed heterozygosity, number of alleles 213 and $F_{S T}$ values between the resulting groups were calculated with Arlequin 3.5. Effective 214 population size was estimated with the coalescent method implemented in NeEstimator v2 (Do et al., 2014). Allelic richness and private allelic richness were calculated applying the rarefaction 216 method implemented in ADZE 1.0 (Szpiech, Jakobsson \& Rosenberg, 2008), with a standardized sample size equal to the smallest sample size across SAMOVA groups, and filtering out loci with more than $50 \%$ missing data in any given group. In order to test the effect of missing data on the private alleles and richness calculations, two additional analyses tolerating $25 \%$ and $0 \%$ missing data were run. calculate hybrid indices between the SAMOVA defined genotypic clusters. This method employs a Bayesian model in which parental and various classes of hybrids form a mixture from which the sample is drawn. Throughout the manuscript we apply the terminology used by NewHybrids when referring to 'hybrid' categories and indices calculated with this software. However, the individuals in this study are admixed individuals but not necessarily inter-specific 'hybrids' (i.e. resulting from inter-species mating) as intended in NewHybrids. and $Y$ ) falls into each of six hybrid classes: pure cluster $X$, pure cluster $Y, F_{1}, F_{2}$, cluster $X$ backcross, or cluster $Y$ backcross. Five independent Markov chain Monte Carlo (MCMC) 
231 analyses were run for each pair of neighboring clusters with at least 300,000 iterations after

23210,000 burnin sweeps. To evaluate if the MCMC reached convergence, we observed the

233 NewHybrids graphical output and visually assessed whether the complete-data log-likelihood

234 trace increased and stabilized in a parameter space region. $\mathrm{P}(\mathrm{z})$ values were averaged among the

235 five independent runs. An individual was considered as belonging to a given class if it is

236 assigned with $\mathrm{P}(\mathrm{z})>0.8$ (Anderson \& Thompson, 2002).

237

238

239 Results

240 Mitochondrial data

241 Out of the 368 individuals included in this study, 344 were sequenced for a fragment of the ND4

242 mtDNA locus. To show the relationships of the two previously unpublished haplotypes

243 KT003209- KT003210, we constructed a haplotype network (Fig. S1). This network constitutes

244 an update from the one produced in 2011 (Zarza, Reynoso \& Emerson, 2011). The new

245 haplotypes connected to haplotypes in the North A clade, and did not alter the previously

246 observed patterns. In the SAMOVA analyses, a change of less than $1 \%$ in FCT was observed at

$247 \mathrm{~K}=10$ (Table A and Fig. A in File S2). Under this $\mathrm{K}, 79 \%$ of the variation can be explained by

248 variation among groups (Table 1). These groups (mt1-mt10 from now onwards, Fig. S2)

249 coincide almost entirely with the haplotype groups previously defined by Zarza, Reynoso \&

250 Emerson (2008). In the current study, SAMOVA analyses detected a subdivision (mt4, mt5)

251 within the Colima mtDNA lineage not found in previous studies. Similarly, individuals forming

252 the North B mtDNA lineage (Zarza, Reynoso \& Emerson, 2008), were here assigned to two 
253 different groups ( $\mathrm{mt} 1$ and $\mathrm{mt} 2$ ). The Oaxaca mtDNA lineage was not recovered in the SAMOVA 254 analyses (Fig. 2).

255

256 Microsatellite data

257 We obtained genotypes for 341 individuals from 49 localities. Number of samples per locality 258 ranged from 1-15 (File S1). Locus Pec25 suffered from null alleles at a frequency higher than $25920 \%$ in twelve localities, thus it was not included in further analyses. Other loci are possibly 260 affected by null alleles but in less than $10 \%$ of the localities, which may reflect local phenomena

261 leading to homozygous excess (Chapuis \& Estoup, 2007). The remaining loci exhibited 9 to 27

262 alleles among the sampled localities. The null hypothesis of random union of gametes was 263 rejected in twelve localities, but only in one location (La Fortuna, see File S1) was deviation

264 from Hardy-Weinberg equilibrium detected in more than one locus (Pec01, Pec03). After Šidák 265 correction $(\mathrm{p}<0.00007)$, the null hypothesis of independence of genotypes at one locus from 266 genotypes at another locus could not be rejected. Pairwise $F_{S T}$ values showed a wide range of 267 genetic differentiation among localities, from non-differentiation $\left(F_{S T}=0\right)$ to a high degree of 268 differentiation (maximum significant $F_{S T}=0.66$; Table S1).

269 SAMOVA analyses with microsatellite data showed a FCT change $<1 \%$ under $\mathrm{K}=5$

270 (from now onwards *Nuc 1-*Nuc 5; Table A, Fig. B in File S2). Under this scenario, around

$27122 \%$ of the variation is explained by variation among groups, whereas $71 \%$ of the variation was

272 explained by variation within individuals (Table 1). These clusters differ from the mtDNA

273 grouping schemes obtained with SAMOVA, but coincide with the clustering resulting from the

274 STRUCTURE analysis as explained below. Allele number, observed heterozygosity, expected

275 heterozygosity, inbreeding coefficient, and effective population size for *Nuc 1-*Nuc 5 are 
276 shown in Table 2. The standardized sample size for the allelic and private allelic richness was 14.

277 Locus Cthe12 was removed from these calculations because it had at least one grouping (i.e.

278 groupings 4 and 5) with more than 50\% missing data. Allelic and private richness mean and

279 variance values are shown in Table 2 . Genetic differentiation ( $F_{S T}$ values) between the

280 SAMOVA groups is shown in Table 3.

281 STRUCTURE results suggest that the most likely number of genotypic clusters is seven,

282 based on the Delta-K $(\Delta K)$ value. However we suspect that $\Delta K$ under $K=7$ is an artifact resulting

283 from the large variation in likelihood values obtained with the previous $\mathrm{K}, \mathrm{K}=6(\mathrm{SD}=1231.92$;

284 Fig. C in File S2). After removing two runs that seemed to be outliers due to lower likelihood

285 values, the $\mathrm{SD}$ under $\mathrm{K}=6$ was greatly reduced (90.45). We then recalculated $\Delta \mathrm{K}$. This time $\mathrm{K}=4$

286 showed the highest $\Delta \mathrm{K}$ (Fig. D in File S2). Individuals were consistently assigned among runs.

287 However these results differ from the clustering obtained with SAMOVA where more groupings

288 were detected in the southern part of the distribution resulting in $\mathrm{K}=5$ (Fig. S2). Additionally, the

289 SAMOVA analyses detected the separation of Ctenosaura acanthura from C. pectinata, whereas

290 STRUCTURE lumped C. acanthura with southern populations of C. pectinata. Thus to establish

291 the most likely number of $\mathrm{K}$ in the southern part of the distribution, and to test for potential

292 equivalents with the SAMOVA analyses and known taxonomy, further analyses were performed

293 on a subset of individuals that included only iguanas collected south of Manzanillo (M in Fig. 1)

294 and along the Gulf of Mexico. We refer to these analyses as South-SS from now onwards.

295 Simulations for 10 million generations were run with $K=2-K=6$, with 10 replicates each. $K=4$

296 showed the highest $\Delta \mathrm{K}$ with consistent results among runs (Fig. E in File S2). When analyzing

297 the entire dataset, only one cluster was detected between Manzanillo and Las Negras (between M

298 and N in Fig. 1; Nuc 3 in Fig. 2 D), whereas two clusters were recognized in the South-SS 
299 analyses (Nuc 3a and Nuc 3b in Fig. 2 E). However, several individuals of Nuc 3a and 3b

300 showed admixed ancestry, indicating weak geographic structure (Fig. 2 E). The division between

301 Nuc 3a and 3b was not detected with SAMOVA (Fig. S2). Two other clusters were identified

302 with the South-SS analyses, one equivalent to *Nuc 4 and the other comprising individuals

303 identified as C. acanthura and equivalent to *Nuc 5 (Fig. S2). Individuals forming these two

304 clusters were consistently assigned among runs and in accordance with the assignment observed 305 when analyzing the entire dataset.

306 Given the weak geographic structure observed between Nuc 3a and Nuc $3 \mathrm{~b}$ and the lack

307 of support for such subdivision with SAMOVA, we take a conservative approach and consider

308 these as forming only one genotypic cluster (equivalent to *Nuc 3 and Nuc 3). Both SAMOVA

309 and STRUCTURE support the distinction between *Nuc 4 (Nuc 4) and *Nuc 5 (Nuc 5, in the

310 South-SS analyses). Taking into account the results of SAMOVA and STRUCTURE we

311 recognize a total of five microsatellite genotypic clusters within the entire distribution of

312 Ctenosaura pectinata + C. acanthura (Fig. 1 and Fig. 2).

313 The microsatellite genotypic clusters detected with STRUCTURE (Nuc 1-Nuc 5) and

314 SAMOVA (*Nuc 1-*Nuc 5) are geographically localized (Fig. 1). The limits of the clusters

315 defined with SAMOVA appear sharp, as this algorithm does not take admixture into account.

316 However, the presence of introgression is supported by the hybrid indices calculated with

317 NewHybrids between SAMOVA genotype clusters (Table 4). Sharp limits of clusters are not

318 observed among the genotypic clusters defined with STRUCTURE but admixed individuals and

319 zones of overlap are clearly observed (Fig. 1 and Fig. 2).

320 There are different levels of geographic concordance between the distribution of mtDNA

321 lineages North A, North B, North C, North D, Colima, Balsas, Guerrero, Oaxaca, and South as 
322 described by Zarza, Reynoso \& Emerson (2008, 2011) and genotypic clusters (Fig. 1 and Fig. 2).

323 In northern Mexico, the distributions of genotypic cluster Nuc 1 (and *Nuc 1) and the North A

324 mtDNA lineage are almost entirely concordant. Further south, in Central Mexico, Nuc 1 overlaps

325 with Nuc 2. Most of the samples in the SAMOVA-equivalent genotypic clusters (*Nuc 1 and

326 *Nuc 2) were assigned to a 'pure' category with NewHybrids (Table 4). Only one F2 was

327 detected and 13 individuals could not be assigned to any category. However four of these

328 individuals had a posterior probability $<0.2$ of being a 'pure' individual. Thus, given the data and

329 the assumptions of the model, those four individuals have a posterior probability $>0.8$ of being

330 hybrids of some sort. Indeed, STRUCTURE plots show signs of interbreeding in the contact

331 zone (Fig. 2 D).

332 Individuals forming Nuc 2 have mtDNA haplotypes belonging to North A, North B,

333 North C, North D and Colima mtDNA lineages. Genotypic cluster Nuc 2 forms a contact zone

334 with Nuc 3. Individuals in this last cluster carry mtDNA haplotypes of Colima, Balsas and

335 Guerrero lineages. The geographically discordant patterns between mtDNA (North C-D,

336 Colima, Balsas) and microsatellite markers in this area (Nuc 2 and Nuc 3) have been previously

337 detected and described (Zarza, Reynoso \& Emerson, 2011). In the equivalent SAMOVA clusters,

33883 individuals were assigned to *Nuc 2 pure class. Pure individuals of *Nuc 3 were not found,

339 however 37 and 4 individuals were assigned to the $\mathrm{F} 2$ and *Nuc 3 backcross hybrid classes

340 respectively (Table 4). Almost 50\% of the individuals forming these clusters could not be

341 assigned to any category. Among these, 83 individuals showed a posterior probability $<0.2$ of

342 belonging to any of the pure classes, thus they might be hybrids of some sort. $F_{S T}$ values between

343 these genotypic clusters are the lowest observed in the pairwise comparisons (Table 3). 

southeast Mexico with mtDNA haplotypes belonging to the Guerrero, Oaxaca and South mtDNA

346 lineages. Most of the individuals were assigned to one of the pure categories in the SAMOVA

347 equivalents *Nuc 3 and *Nuc 4 (Table 4). Only two *Nuc 3 back-crosses were found and 27

348 were not assigned to any category. None of them had posterior probability $<0.2$ of belonging to 349 any pure class.

$350 \quad$ Nuc 4 and Nuc 5 do not overlap. All individuals in the SAMOVA equivalents *Nuc 4 351 and $*$ Nuc 5 were assigned to a pure category with a posterior probability $>0.8$. Nuc 5 includes

352 individuals described as Ctenosaura acanthura, collected in eastern Mexico. It is geographically 353 concordant with the distribution of a mtDNA lineage closely related to the Southern mtDNA

354 lineage (2008). Admixture between C. acanthura and C. pectinata is only evident in Zapotitlán 355 de las Salinas (denoted as ' $Z$ ' in Fig. 1), with individuals carrying C. acanthura mtDNA

356 haplotypes but with nuclear ancestry of Nuc 3 and Nuc 5. The NewHybrids analysis between

$357 *$ Nuc 3 and *Nuc 5 detected two F2 individuals. One was collected in Zapotitlán de las Salinas, 358 and the other in Apatzingán (denoted as ' $Z$ ' and ' $A$ ' respectively in Fig. 1). The latter locality is 359 not geographically close to the distribution limits of Nuc 5 (or *Nuc 5). Thus the potential of 360 long distance dispersal, perhaps human mediated, should be investigated. The remaining of the 361 individuals was assigned to one of the pure categories and only four were not assigned to any 362 hybrid or pure category. 363

\section{Discussion}




\section{Introgression and geographic discordance between mtDNA and}

\section{6 nuclear markers}

Different degrees of discordance are observed in the geographic distribution of mtDNA

368

369

370

371

372

373

374

375

376

377

378

379

380

381

382

383

384

385

386

387

lineages and microsatellite genotypic clusters across the range of Ctenosaura pectinata. At one end of the spectrum, mtDNA North A lineage is almost entirely concordant with Nuc 1 cluster.

At the opposite end of the spectrum, mtDNA lineages distributed along the central western coast of Mexico exhibit a striking discordant pattern where up to six geographically distinct mtDNA lineages (North A, North B, North C, North D, Colima, Balsas) co-occur with only two nuclear clusters (Nuc 2 and Nuc 3). This discordance between maternally and biparentally inherited markers in C. pectinata might be the result of several processes acting alone, in concert or at different points in time. For example, a suitable explanation might be a scenario of short term refugia where populations decline throughout the range, resulting in isolation, followed by recent range expansion and male biased dispersal (Dubey et al., 2008; Johansson, Surget-Groba \& Thorpe, 2008; Ujvari, Dowton \& Madsen, 2008; Zarza, Reynoso \& Emerson, 2011; Toews \& Brelsford, 2012). The discordant pattern can also be the result of coalescence stochasticity (Irwin, 2002; Hickerson et al., 2010), selection of mtDNA (Dowling, Friberg \& Lindell, 2008), or differences in effective population size between mtDNA and nuclear markers.

Introgression, along current and past contact zones, may have also contributed to the patterns of geographic discordance in conjunction with other demographic phenomena. For example, it has been suggested that, in contact zones, selection and genetic drift can lead to mtDNA introgressing further and faster than nDNA. This is because mitochondrial genomes are less likely to hitchhike with a region under selection that prevents introgression (Ballard \& Whitlock, 2004; Petit \& Excoffier, 2009; Milá et al., 2013). Additionally, in small populations, 
388

389

390

391

392

393

394

395

396

397

398

399

400

401

402

403

404

405

406

407

408

409

410

genetic drift can allow the fixation of slightly deleterious alleles in the mtDNA of one population

resulting in lower fitness than a related species in the same area. Selection could then drive

introgression of mtDNA from the more fit population into the less fit population (Ballard \&

Whitlock, 2004). Furthermore, it is possible that some contact zones have changed location

(Barton \& Hewitt, 1985; Buggs, 2007), or that others have disappeared entirely as a result of

complex climate mediated cycles of range expansion and contraction, or due to other

phenomena. It is difficult to disentangle the effect of these processes with the currently available

data. Sampling more finely along contact zones, and sequencing additional nuclear markers may

permit coalescence analyses (Singhal \& Moritz, 2012). Behavioral studies may also be

informative to evaluate the effects of ecological, demographic, historical, and stochastic factors shaping the discordant patterns.

Interestingly, pairs of inter-breeding nuclear clusters with different levels of divergence

occur throughout the distribution of Ctenosaura pectinata. For example, allele frequency

divergence between *Nuc 1 and *Nuc 2 is 0.18952 , whereas it is 0.14815 between *Nuc 2 and

*Nuc 3 (Table 3). Assignment of individuals to pure and hybrid classes also shows that contact

zones have different hybrid compositions. A higher proportion of individuals were assigned to a

pure class when analyzing *Nuc 1 and $*$ Nuc $2(89 \%)$ than when analyzing *Nuc 2 and *Nuc 3

(36\%). This is also observed in the STRUCTURE plots which reveal Nuc 2 and Nuc 3 admixed individuals more frequently than admixed Nuc 1 and Nuc 2 .

Thus Ctenosaura pectinata constitutes an excellent system to better understand the process of speciation by studying the effects of introgression between genotypic clusters at different stages of divergence. Furthermore, this system potentially enables the comparison of evolutionary patterns and processes with contact zones in temperate and other tropical regions of 
411 the world (Leaché \& McGuire, 2006; McGuire et al., 2007; Singhal \& Moritz, 2012; Miraldo et

412 al., 2013; Milá et al., 2013).

413

414 Implications for Ctenosaura pectinata taxonomy and conservation

415 Our results suggest that there are five nuclear genotypic clusters forming what is

416 currently considered Ctenosaura pectinata. Individuals forming the Nuc 1 cluster belong to the

417 North A mtDNA lineage. Thus Nuc 1 and North A mtDNA lineages are geographically

418 concordant. The distribution of this genotypic cluster coincides with the distribution of $C$.

419 brachylopha as revised by Bailey (1928) using morphological data (i.e. states of Sinaloa,

420 Nayarit, North of Jalisco and Isla Isabel; Fig. 1 and Fig. 2).

421 The observed concordance in the geographic distribution of nuclear and mtDNA might be

422 the result of stochastic coalescent processes, which is particularly true in taxa with low dispersal

423 rates, as is the case for iguanas (Irwin, 2002). Other phenomena such as natural selection could

424 be shaping the observed pattern, however this cannot be evaluated with the currently available

425 data. Another possibility is that the formation of a biogeographic barrier affected the distribution

426 of Nuc 1 and North A. Their southern distribution limit coincides approximately with the

427 TMVB. This geographic feature has been proposed as a geographic barrier for several lowland

428 taxa (Devitt, 2006; Mulcahy, Morrill \& Mendelson, 2006; De-Nova et al., 2012; Arbeláez-

429 Cortés, Milá \& Navarro-Sigüenza, 2014; Arbeláez-Cortés, Roldán-Piña \& Navarro-Sigüenza,

430 2014; Suárez-Atilano, Burbrink \& Vázquez-Domínguez, 2014; Blair et al., 2015). However,

431 given the complex geological history of the area, the TMVB barrier might not have affected all

432 taxa equally (Mastretta-Yanes et al., 2015). Indeed, despite this barrier, gene flow has occurred 
433 between Nuc 1 and the neighboring Nuc 2 at the limits of their distribution in the vicinity of the 434 TMVB.

435 Gene flow has also been observed in a contact zone between Nuc 1 and Ctenosaura 436 hemilopha in the northern edge of Nuc 1 distribution (Zarza, Reynoso \& Emerson, 2008). Along 437 both, northern and southern edges, gene flow seems to be limited to a narrow area. According to 438 hybrid zone theory, several factors affect the extent, maintenance and shifting of hybrid zones: 439 dispersal, selection, recombination rates and time since secondary contact (Barton \& Hewitt, 440 1985). The effect of these processes needs to be further investigated, ideally at the genomic level. 441 The paradigm that lack of gene flow is a prerequisite to maintain species integrity is 442 shifting (Abbott et al., 2013). In recent years evidence has accumulated suggesting that gene

443 flow is an integral part of the process of speciation and that divergence can occur in the presence 444 of gene flow (Mallet, 1995; Pinho \& Hey, 2010; Leaché et al., 2014; Zarza et al., 2016; Leavitt et 445 al., 2017). Indeed, if reproductive barriers have emerged in secondary contact zones, it is 446 uncertain whether barriers to gene flow will be strengthened or broken down due to 447 recombination and admixture (Barton \& Hewitt, 1985; Abbott et al., 2013).

448 Despite the levels of gene flow detected and given the geographic concordance in the 449 distribution of mtDNA and nuclear markers, the geographic limits that coincide with the 450 geographic limits of other species, and the morphological signal detected by Bailey (1928), we 451 suggest the resurrection of the name Ctenosaura brachylopha for populations inhabiting 452 northwestern Mexico.

453 The distribution of Nuc 2 and Nuc 3 genetic clusters are geographically discordant with 454 the distribution of mtDNA lineages in central Mexico (North A-D, Colima, Balsas). Maternal 455 lineages are more deeply structured than the genotypic clusters. The distribution of the 
456 maternally and paternally inherited markers and the high number of sampled admixed

457 individuals suggest that, although there is some substructure in the area, gene flow among

458 populations has been ongoing. Given that the holotype locality is labeled as "Colima"

459 (Wiegmann, 1834) we suggest that these genotypic clusters keep the historical name Ctenosaura 460 pectinata (Fig. 2).

461 Iguanas described as Ctenosaura acanthura also form a coherent nuclear cluster (Nuc 5)

462 that is concordant with a mtDNA lineage closely related to the South clade (Zarza, Reynoso \&

463 Emerson, 2008). Thus the name $C$. acanthura should continue to be applied to populations of

464 spiny-tailed iguanas in the coast of the Gulf of Mexico. Introgression is apparent in the area of

465 Zapotitlán de las Salinas (Fig. 1), where individuals carry mtDNA haplotypes typical of $C$.

466 acanthura and some alleles of Nuc 3 and Nuc 5.

467 Nuc 4 is almost entirely geographically concordant with the South mtDNA lineage, but

468 also overlaps with the Oaxaca and Guerrero lineages. Thus Nuc 4 deserves taxonomic

469 recognition at the species level, and awaits full description until morphological data is gathered

470 and analyzed. In the meantime, we propose that these populations are recognized as an

471 independent Evolutionary Significant Unit (Moritz, 1994) within Ctenosaura pectinata.

472 We are aware that the modifications in taxonomy proposed in this paper are based mostly

473 on molecular and geographic evidence. Morphological data have not revealed the existence of

474 divisions within Ctenosaura pectinata (Köhler, Schroth \& Streit, 2000), except for the work of

475 Bailey (Bailey, 1928). He realized that C. brachylopha resembles C. pectinata but may be

476 distinguished from it by having a median dorsal crest that does not extend over the sacral region

477 and that it is formed by $65-75$ scales. He also noticed that the first seven whorls of spinous

478 caudal scales are separated from each other by three rows of small flat scales. In C. pectinata the 
479 first five whorls of spinous scales are separated from each other by three rows of small flat

480 scales, but subsequent whorls of spinous scales are separated by two rows of flat scales up the

481 middle of the length of the tail (Bailey, 1928). These and other morphological characters need to

482 be studied in depth, with a large sample and with more modern statistical methods to validate

483 their utility to distinguish between groups within C. pectinata. Color may be an important

484 character too. Individuals from northern Mexico exhibit a yellow coloration (Fig. S3), those in

485 central Mexico show blue and orange patterns, and individuals from the south are black and

486 white. Bailey studied stuffed or alcohol-preserved specimens that most likely lost their original

487 color, so he did not address this character.

Our molecular approach has uncovered several genotypic clusters. However this may

present challenges for the field biologist working in areas with high levels of admixture (i.e. determine if coloration patterns or morphological characters of individuals outside the contact zones provide information for their assignment to a specific genotypic cluster.

This work provides important knowledge with profound implications in conservation, wildlife management and forensics. Ctenosaura pectinata sensu lato faces illegal hunting, poaching and habitat loss (Reynoso, 2000; Aguirre-Hidalgo, 2007; Faria et al., 2010). It is considered as a threatened species under the Mexican law (SEMARNAT, 2002), awaiting IUCN evaluation, and may not receive proper protection if its genetic composition and distribution is not taken into account (Frankham, 2006). Measures have been taken to protect its populations, however there are not genetics-based strategies to re-introduce confiscated individuals and/or to avoid admixture in populations that may lead to loss of diversity through hybridization, 
502 reduced viability or fertility in the case of genetic incompatibilities, reduced population fitness

503 due to selective disadvantage of intermediate genotypes or loss of advantageous parental traits

504 (Lynch, 1991; Burke \& Arnold, 2001). Furthermore, our results suggest that C. pectinata, a

505 species already recognized as threatened, is actually composed of multiple genotypic clusters

506 that might be at a higher risk than previously thought, given their reduced geographical

507 distributions and effective population sizes (Bickford et al., 2007).

508

509 Acknowledgements

510

511 EZ and VHR would like to dedicate this work to the memory of Wendoli Medina Mantecón, a

512 close collaborator and friend who will be remembered, among other things, for her efforts and 513 dedication to the conservation of iguanas and other endangered species.

\section{References}

517 Abbott R., Albach D., Ansell S., Arntzen JW., Baird SJE., Bierne N., Boughman J., Brelsford A., 518 Buerkle CA., Buggs R., Butlin RK., Dieckmann U., Eroukhmanoff F., Grill A., Cahan 519 SH., Hermansen JS., Hewitt G., Hudson AG., Jiggins C., Jones J., Keller B., Marczewski T., Mallet J., Martinez-Rodriguez P., Möst M., Mullen S., Nichols R., Nolte AW., Parisod C., Pfennig K., Rice AM., Ritchie MG., Seifert B., Smadja CM., Stelkens R., Szymura JM., Väinölä R., Wolf JBW., Zinner D. 2013. Hybridization and speciation. Journal of Evolutionary Biology 26:229-246. DOI: 10.1111/j.1420-9101.2012.02599.x. 
524 Aguirre-Hidalgo V. 2007. Demography and genetic diversity of the Mexican black iguana

525

526

527

528

529

530

531

532

533

534

535

536

537

538

539

540

541

542

543

544

545

546

547

548

549

550

551

552

553

Ctenosaura pectinata. Plymouth: University of Plymouth, School of Biological Sciences.

Aljanabi SM., Martinez I. 1997. Universal and rapid salt-extraction of high quality genomic DNA for PCR-based techniques. Nucleic Acids Research 25:4692-4693. DOI: 10.1093/nar/25.22.4692.

Anderson EC. 2008. Bayesian inference of species hybrids using multilocus dominant genetic markers. Philosophical Transactions of the Royal Society of London B: Biological Sciences 363:2841-2850. DOI: 10.1098/rstb.2008.0043.

Anderson EC., Thompson EA. 2002. A Model-Based Method for Identifying Species Hybrids Using Multilocus Genetic Data. Genetics 160:1217-1229.

Arbeláez-Cortés E., Milá B., Navarro-Sigüenza AG. 2014. Multilocus analysis of intraspecific differentiation in three endemic bird species from the northern Neotropical dry forest. Molecular Phylogenetics and Evolution 70:362-377. DOI: 10.1016/j.ympev.2013.10.006.

Arbeláez-Cortés E., Roldán-Piña D., Navarro-Sigüenza AG. 2014. Multilocus phylogeography and morphology give insights into the recent evolution of a Mexican endemic songbird: Vireo hypochryseus. Journal of Avian Biology 45:253-263. DOI: 10.1111/j.1600048X.2013.00335.x.

Arèvalo E., Davis SK., Sites JW. 1994. Mitochondrial DNA Sequence Divergence and Phylogenetic Relationships among Eight Chromosome Races of the Sceloporus grammicus Complex (Phrynosomatidae) in Central Mexico. Systematic Biology 43:387418. DOI: $10.1093 /$ sysbio/43.3.387.

Bailey JW. 1928. A revision of the lizards of the genus Ctenosaura. Proceedings of the United States National Museum 73:1-55.

Ballard JWO., Whitlock MC. 2004. The incomplete natural history of mitochondria. Molecular Ecology 13:729-744. DOI: 10.1046/j.1365-294X.2003.02063.x.

Bandelt HJ., Forster P., Rohl A. 1999. Median-joining networks for inferring intraspecific phylogenies. Molecular Biology and Evolution 16:37-48.

Barton NH., Hewitt GM. 1985. Analysis of hybrid zones. Annual review of Ecology and Systematics 6:113-148. 
554 Bauer AM., Parham JF., Brown RM., Stuart BL., Grismer L., Papenfuss TJ., Böhme W., Savage

555

556

557

558

559

560

561

562

563

564

565

566

567

568

569

570

571

572

573

574

575

576

577

578

579

580

581

582

583

JM., Carranza S., Grismer JL., Wagner P., Schmitz A., Ananjeva NB., Inger RF. 2011. Availability of new Bayesian-delimited gecko names and the importance of characterbased species descriptions. Proceedings of the Royal Society of London B: Biological Sciences 278:490-492. DOI: 10.1098/rspb.2010.1330.

Bickford D., Lohman DJ., Sodhi NS., Ng PKL., Meier R., Winker K., Ingram KK., Das I. 2007. Cryptic species as a window on diversity and conservation. Trends in ecology \& evolution 22:148-155. DOI: 10.1016/j.tree.2006.11.004.

Blair C., Méndez de la Cruz FR., Law C., Murphy RW. 2015. Molecular phylogenetics and species delimitation of leaf-toed geckos (Phyllodactylidae: Phyllodactylus) throughout the Mexican tropical dry forest. Molecular Phylogenetics and Evolution 84:254-265. DOI: 10.1016/j.ympev.2015.01.003.

Blázquez MC., Rodríguez Estrella R., Munguía Vega A. 2006. Characterization of 10 microsatellite loci in the spiny-tailed iguana Ctenosaura hemilopha. Molecular Ecology Notes 6:753-755.

Bryson RW., García-Vázquez UO., Riddle BR. 2012. Relative roles of Neogene vicariance and Quaternary climate change on the historical diversification of bunchgrass lizards (Sceloporus scalaris group) in Mexico. Molecular Phylogenetics and Evolution 62:447457. DOI: 10.1016/j.ympev.2011.10.014.

Bryson RW., Linkem CW., Pavón-Vázquez CJ., Oca AN-M de., Klicka J., McCormack JE. 2017. A phylogenomic perspective on the biogeography of skinks in the Plestiodon brevirostris group inferred from target enrichment of ultraconserved elements. Journal of Biogeography 44:2033-2044. DOI: 10.1111/jbi.12989.

Buggs RJA. 2007. Empirical study of hybrid zone movement. Heredity 99:301-312. DOI: 10.1038/sj.hdy.6800997.

Burke JM., Arnold ML. 2001. Genetics and the fitness of hybrids. Annual Review of Genetics 35:31-52. DOI: 10.1146/annurev.genet.35.102401.085719.

Chapuis M-P., Estoup A. 2007. Microsatellite Null Alleles and Estimation of Population Differentiation. Molecular Biology and Evolution 24:621-631. DOI: 10.1093/molbev/msl191. 
584 Daza JM., Smith EN., Páez VP., Parkinson CL. 2009. Complex evolution in the Neotropics: The

585

586

587

588

589

590

591

592

593

594

595

596

597

598

599

600

601

602

603

604

605

606

607

608

609

610

611

612

613 origin and diversification of the widespread genus Leptodeira (Serpentes: Colubridae). Molecular Phylogenetics and Evolution 53:653-667. DOI: 10.1016/j.ympev.2009.07.022.

De-Nova JA., Medina R., Montero JC., Weeks A., Rosell JA., Olson ME., Eguiarte LE., Magallón S. 2012. Insights into the historical construction of species-rich Mesoamerican seasonally dry tropical forests: the diversification of Bursera (Burseraceae, Sapindales). New Phytologist 193:276-287. DOI: 10.1111/j.1469-8137.2011.03909.x.

Devitt TJ. 2006. Phylogeography of the Western Lyre snake (Trimorphodon biscutatus): testing arid land biogeographical hypotheses across the Nearctic-Neotropical transition. Molecular Ecology 15:4387-4407.

Do C., Waples RS., Peel D., Macbeth GM., Tillett BJ., Ovenden JR. 2014. NeEstimator v2: reimplementation of software for the estimation of contemporary effective population size (Ne) from genetic data. Molecular Ecology Resources 14:209-214. DOI: 10.1111/17550998.12157.

Dowling DK., Friberg U., Lindell J. 2008. Evolutionary implications of non-neutral mitochondrial genetic variation. Trends in Ecology \& Evolution 23:546-554.

Dubey S., Brown GP., Madsen T., Shine R. 2008. Male-biased dispersal in a tropical Australian snake (Stegonotus cucullatus, Colubridae). Molecular Ecology 17:3506-3514. DOI: 10.1111/j.1365-294X.2008.03859.x.

Dupanloup I., Schneider S., Excoffier L. 2002. A simulated annealing approach to define the genetic structure of populations. Molecular Ecology 11:2571-2581.

Earl DA., vonHoldt BM. 2012. STRUCTURE HARVESTER: a website and program for visualizing STRUCTURE output and implementing the Evanno method. Conservation Genetics Resources 4:359-361. DOI: 10.1007/s12686-011-9548-7.

Evanno G., Regnaut S., Goudet J. 2005. Detecting the number of clusters of individuals using the software STRUCTURE: a simulation study. Molecular Ecology 14:2611-2620.

Excoffier L., Lischer HEL. 2010. Arlequin suite ver 3.5: a new series of programs to perform population genetics analyses under Linux and Windows. Molecular Ecology Resources 10:564-567. DOI: 10.1111/j.1755-0998.2010.02847.x. 
614 Faria C. 2008. Conservation genetics of the Black Iguana - testing for multiple paternity and

615

616

617

618

619

620

621

622

623

624

625

626

627

628

629

630

631

632

633

634

635

636

637

638

639

640

641

642

643

644

assessing the use of microsatellites for forensic genetics. Norwich: Univeristy of East Anglia,.

Faria CMA., Zarza E., Reynoso VH., Emerson BC. 2010. Predominance of single paternity in the black spiny-tailed iguana: conservation genetic concerns for female-biased hunting. Conservation Genetics 11:1645-1652. DOI: 10.1007/s10592-010-0047-2.

Frankham R. 2006. Evolutionary conservation genetics. In: Fox CW, Wolf JB eds. Evolutionary Genetics, Concepts and Case Studies. New York: Oxford University Press, 502-512.

Gompert Z. 2012. Population genomics as a new tool for wildlife management. Molecular Ecology 21:1542-1544. DOI: 10.1111/j.1365-294X.2012.05471.x.

Greenbaum E., Smith EN., de Sá RO. 2011. Molecular systematics of the Middle American genus Hypopachus (Anura: Microhylidae). Molecular Phylogenetics and Evolution 61:265-277. DOI: 10.1016/j.ympev.2011.07.002.

Haenel GJ. 2017. Introgression of mtDNA in Urosaurus lizards: historical and ecological processes. Molecular Ecology 26:606-623. DOI: 10.1111/mec.13930.

Hasbún CR., Gómez A., Köhler G., Lunt DH. 2005. Mitochondrial DNA phylogeography of the Mesoamerican spiny tailed lizards (Ctenosaura quinquecarinata complex): historical biogeography, species status and conservation. Molecular Ecology 14:3095-3107.

Haus T., Roos C., Zinner D. 2013. Discordance Between Spatial Distributions of YChromosomal and Mitochondrial Haplotypes in African Green Monkeys (Chlorocebus spp.): A Result of Introgressive Hybridization or Cryptic Diversity? International Journal of Primatology 34:986-999. DOI: 10.1007/s10764-013-9717-5.

Hickerson MJ., Carstens BC., Cavender-Bares J., Crandall KA., Graham CH., Johnson JB., Rissler L., Victoriano PF., Yoder AD. 2010. Phylogeography's past, present, and future: 10 years after Avise, 2000. Molecular Phylogenetics and Evolution 54:291-301. DOI: 10.1016/j.ympev.2009.09.016.

Irwin DE. 2002. Phylogeographic breaks without geographic barriers to gene flow. Evolution; international journal of organic evolution 56:2383-2394.

Johansson H., Surget-Groba Y., Thorpe RS. 2008. Microsatellite data show evidence for malebiased dispersal in the Caribbean lizard Anolis roquet. Molecular Ecology 17:4425-4432. Köhler G. 2002. Schwarzleguane - Lebensweise, Haltung, Zucht,. Offenbach: Herpeton. 
645 Köhler G., Schroth W., Streit B. 2000. Systematics of the Ctenosaura group of lizards (Reptilia : 646 Sauria : Iguanidae). Amphibia-Reptilia 21:177-191.

647 Kronforst MR. 2012. Mimetic Butterflies Introgress to Impress. PLoS Genet 8:e1002802. DOI: $648 \quad$ 10.1371/journal.pgen.1002802.

649 Kumar V., Lammers F., Bidon T., Pfenninger M., Kolter L., Nilsson MA., Janke A. 2017. The 650 evolutionary history of bears is characterized by gene flow across species. Scientific 651 Reports 7:46487. DOI: 10.1038/srep46487.

652 Leaché AD., Fujita MK. 2010. Bayesian species delimitation in West African forest geckos 653 (Hemidactylus fasciatus). Proceedings of the Royal Society B: Biological Sciences 654 277:3071-3077. DOI: 10.1098/rspb.2010.0662.

655 Leaché AD., Harris RB., Rannala B., Yang Z. 2014. The Influence of Gene Flow on Species 656 Tree Estimation: A Simulation Study. Systematic Biology 63:17-30. DOI: $10.1093 /$ sysbio/syt049.

659

Leaché AD., McGuire JA. 2006. Phylogenetic relationships of horned lizards (Phrynosoma)

660 based on nuclear and mitochondrial data: Evidence for a misleading mitochondrial gene

661 tree. Molecular Phylogenetics and Evolution 39:628-644.

Leavitt DH., Marion AB., Hollingsworth BD., Reeder TW. 2017. Multilocus phylogeny of 662 alligator lizards (Elgaria, Anguidae): Testing mtDNA introgression as the source of discordant molecular phylogenetic hypotheses. Molecular Phylogenetics and Evolution 110:104-121. DOI: 10.1016/j.ympev.2017.02.010.

Lynch M. 1991. The Genetic Interpretation of Inbreeding Depression and Outbreeding

Mallet J. 1995. A species definition for the modern synthesis. Trends in Ecology \& Evolution 10:294-299. DOI: 10.1016/0169-5347(95)90031-4.

Mallet J. 2005. Hybridization as an invasion of the genome. Trends in Ecology \& Evolution 20:229-237.

Mallet J., Besansky N., Hahn MW. 2016. How reticulated are species? BioEssays: News and Reviews in Molecular, Cellular and Developmental Biology 38:140-149. DOI: 10.1002/bies.201500149.

Malone CL., Wheeler T., Taylor JF., Davis SK. 2000. Phylogeography of the Caribbean rock iguana (Cyclura): Implications for conservation and insights on the biogeographic history 
676

677

678

679

680

681

682

683

684

685

686

687

688

689

690

691

692

693

694

695

696

697

698

699

700

701

702

703

704

705

of the West Indies. Molecular Phylogenetics and Evolution 17:269-279. DOI: 10.1006/mpev.2000.0836.

Mastretta-Yanes A., Moreno-Letelier A., Piñero D., Jorgensen TH., Emerson BC. 2015.

Biodiversity in the Mexican highlands and the interaction of geology, geography and climate within the Trans-Mexican Volcanic Belt. Journal of Biogeography 42:15861600. DOI: $10.1111 /$ jbi.12546.

McGuire JA., Linkem CW., Koo MS., Hutchison DW., Lappin AK., Orange DI., Lemos-Espinal J., Riddle BR., Jaeger JR. 2007. Mitochondrial introgression and incomplete lineage sorting through space and time: Phylogenetics of crotaphytid lizards. Evolution 61:28792897. DOI: $10.1111 / \mathrm{j} .1558-5646.2007 .00239 . x$.

Milá B., Surget-Groba Y., Heulin B., Gosá A., Fitze PS. 2013. Multilocus phylogeography of the common lizard Zootoca vivipara at the Ibero-Pyrenean suture zone reveals lowland barriers and high-elevation introgression. BMC Evolutionary Biology 13:192. DOI: 10.1186/1471-2148-13-192.

Miraldo A., Faria C., Hewitt GM., Paulo OS., Emerson BC. 2013. Genetic analysis of a contact zone between two lineages of the ocellated lizard (Lacerta lepida Daudin 1802) in southeastern Iberia reveal a steep and narrow hybrid zone. Journal of Zoological Systematics and Evolutionary Research 51:45-54. DOI: 10.1111/jzs.12005.

Moritz C. 1994. Defining 'Evolutionarily Significant Units' for conservation. Trends in Ecology \& Evolution 9:373-375. DOI: 10.1016/0169-5347(94)90057-4.

Mulcahy DG., Morrill BH., Mendelson JR. 2006. Historical biogeography of lowland species of toads (Bufo) across the Trans-Mexican Neovolcanic Belt and the Isthmus of Tehuantepec. Journal of Biogeography 33:1889-1904.

Myers N., Mittermeier RA., Mittermeier CG., da Fonseca GAB., Kent J. 2000. Biodiversity hotspots for conservation priorities. Nature 403:853-858. DOI: 10.1038/35002501.

Nieto-Montes de Oca A., Barley AJ., Meza-Lázaro RN., García-Vázquez UO., Zamora-Abrego JG., Thomson RC., Leaché AD. 2017. Phylogenomics and species delimitation in the knob-scaled lizards of the genus Xenosaurus (Squamata: Xenosauridae) using ddRADseq data reveal a substantial underestimation of diversity. Molecular Phylogenetics and Evolution 106:241-253. DOI: 10.1016/j.ympev.2016.09.001. 
706 Ornelas JF., Sosa V., Soltis DE., Daza JM., González C., Soltis PS., Gutiérrez-Rodríguez C.,

707

708

709

710

711

712

713

714

715

716

717

718

719

720

721

722

723

724

725

726

727

728

729

730

731

732

733

734

Monteros AE de los., Castoe TA., Bell C., Ruiz-Sanchez E. 2013. Comparative Phylogeographic Analyses Illustrate the Complex Evolutionary History of Threatened Cloud Forests of Northern Mesoamerica. PLOS ONE 8:e56283. DOI: 10.1371/journal.pone.0056283.

Pardo-Diaz C., Salazar C., Baxter SW., Merot C., Figueiredo-Ready W., Joron M., McMillan WO., Jiggins CD. 2012. Adaptive Introgression across Species Boundaries in Heliconius Butterflies. PLoS Genet 8:e1002752. DOI: 10.1371/journal.pgen.1002752.

Petit RJ., Excoffier L. 2009. Gene flow and species delimitation. Trends in Ecology \& Evolution 24:386-393. DOI: 10.1016/j.tree.2009.02.011.

Pilot M., Greco C., vonHoldt BM., Randi E., Jędrzejewski W., Sidorovich VE., Konopiński MK., Ostrander EA., Wayne RK. 2018. Widespread, long-term admixture between grey wolves and domestic dogs across Eurasia and its implications for the conservation status of hybrids. Evolutionary Applications 11:662-680. DOI: 10.1111/eva.12595.

Pinho C., Hey J. 2010. Divergence with Gene Flow: Models and Data. Annual Review of Ecology, Evolution, and Systematics 41:215-230. DOI: 10.1146/annurev-ecolsys102209-144644.

Pringle EG., Ramírez SR., Bonebrake TC., Gordon DM., Dirzo R. 2012. Diversification and phylogeographic structure in widespread Azteca plant-ants from the northern Neotropics. Molecular Ecology 21:3576-3592. DOI: 10.1111/j.1365-294X.2012.05618.x.

Pritchard JK., Stephens M., Donnelly P. 2000. Inference of population structure using multilocus genotype data. Genetics 155:945-959.

R Core Team 2012. A language and environment for statistical computing. Vienna, Austria: $\mathrm{R}$ Foundation for Statistical Computing.

Reynoso VH. 2000. Cazando iguana negra: un problema mayor del que parece. Memorias de la VI reunión nacional de herpetología. Mexico.

Rittmeyer EN., Austin CC. 2012. The effects of sampling on delimiting species from multi-locus sequence data. Molecular Phylogenetics and Evolution 65:451-463. DOI: 10.1016/j.ympev.2012.06.031. 
735 Rodríguez-Gómez F., Ornelas JF. 2018. Genetic structuring and secondary contact in the white-

736

737

738

739

740

741

742

743

744

745

746

747

748

749

750

751

752

753

754

755

756

757

758

759

760

761

762

763

764

765

chested Amazilia hummingbird species complex. Journal of Avian Biology 49:jav-01536. DOI: $10.1111 /$ jav.01536.

Rousset F. 2008. GENEPOP ' 007: a complete re-implementation of the GENEPOP software for Windows and Linux. Molecular Ecology Resources 8:103-106.

Seehausen O. 2004. Hybridization and adaptive radiation. Trends in Ecology \& Evolution 19:198-207. DOI: 10.1016/j.tree.2004.01.003.

SEMARNAT. 2002. NOM-059-ECOL-2001. Diario Oficial de la Federación (segunda sección), Miércoles 6 de marzo.

Singhal S., Moritz C. 2012. Testing hypotheses for genealogical discordance in a rainforest lizard. Molecular ecology 21:5059-5072. DOI: 10.1111/j.1365-294X.2012.05747.x.

Smith HM., Taylor EH. 1950. An annotated check list and key to the reptiles of Mexico exclusive of snakes. United States National Museum Bulletin 199:vi, 253.

Streicher JW., Devitt TJ., Goldberg CS., Malone JH., Blackmon H., Fujita MK. 2014.

Diversification and asymmetrical gene flow across time and space: lineage sorting and hybridization in polytypic barking frogs. Molecular Ecology 23:3273-3291. DOI: 10.1111/mec.12814.

Suárez-Atilano M., Burbrink F., Vázquez-Domínguez E. 2014. Phylogeographical structure within Boa constrictor imperator across the lowlands and mountains of Central America and Mexico. Journal of Biogeography 41:2371-2384. DOI: 10.1111/jbi.12372.

Szpiech ZA., Jakobsson M., Rosenberg NA. 2008. ADZE: a rarefaction approach for counting alleles private to combinations of populations. Bioinformatics (Oxford, England) 24:2498-2504. DOI: 10.1093/bioinformatics/btn478.

Tamura K., Nei M. 1993. Estimation of the number of nucleotide substitutions in the control region of mitochondrial DNA in humans and chimpanzees. Molecular biology and evolution 10:512-526.

Toews DPL., Brelsford A. 2012. The biogeography of mitochondrial and nuclear discordance in animals. Molecular ecology 21:3907-3930. DOI: 10.1111/j.1365-294X.2012.05664.x.

Ujvari B., Dowton M., Madsen T. 2008. Population genetic structure, gene flow and sex-biased dispersal in frillneck lizards (Chlamydosaurus kingii). Molecular Ecology 17:3557-3564. DOI: 10.1111/j.1365-294X.2008.03849.x.

Peer) reviewing PDF | (2016:10:13787:2:0:REVIEW 20 Feb 2019) 
766 Wiegmann AF. 1834. Herp. Mex. Berlin.

767 Zaldivar-Riverón A., Leon-Regagnon V., de Oca ANM. 2004. Phylogeny of the Mexican coastal

768 leopard frogs of the Rana berlandieri group based on mtDNA sequences. Molecular

$769 \quad$ Phylogenetics and Evolution 30:38-49.

770 Zarza E., Faircloth BC., Tsai WLE., Bryson RW., Klicka J., McCormack JE. 2016. Hidden

771 histories of gene flow in highland birds revealed with genomic markers. Molecular

772 Ecology 25:5144-5157. DOI: 10.1111/mec.13813.

773 Zarza Franco GE. 2008. Phylogeography and genetic analysis of secondary contact zones of

774 Ctenosaura pectinata and related species. Ph.D. dissertation Thesis. Norwich, UK:

$775 \quad$ Univeristy of East Anglia.

776 Zarza E., Pereyra RT., Reynoso VH., Emerson BC. 2009. Isolation and characterization of

777 polymorphic microsatellite markers in the black spiny tailed iguana (Ctenosaura

778 pectinata) and their cross-utility in other Ctenosaura. Molecular ecology resources

779 9:117-119.

780 Zarza E., Reynoso VH., Emerson BC. 2008. Diversification in the northern neotropics:

781 mitochondrial and nuclear DNA phylogeography of the iguana Ctenosaura pectinata and

782 related species. Molecular ecology 17:3259-3275.

783 Zarza E., Reynoso VH., Emerson BC. 2011. Discordant patterns of geographic variation between

784 mitochondrial and microsatellite markers in the Mexican black iguana (Ctenosaura

785 pectinata) in a contact zone. Journal of Biogeography 38:1394-1405.

786 Zarza E., Reynoso VH., Emerson BC. 2016. Genetic Tools for Assisting Sustainable

787

788 Management and Conservation of the Spiny-Tailed Iguana, Ctenosaura pectinata. Herpetological Conservation and Biology 11:255-264.

789 


\section{$791 \quad$ Figures}

792 Figure 1. Geographic distribution of mtDNA lineages and genotypic clusters within

793 Ctenosaura pectinata and $\boldsymbol{C}$. acanthura. Lines represent the geographical limits of the mtDNA

794 lineages. Colors and lineage names follow the scheme shown in the haplotype network (Fig. S1).

795 Pie charts show proportion of ancestry among individuals sampled in each locality with colors

796 equivalent to STRUCTURE clusters. A: Apatzingán, H: contact zone between C. hemilopha and

797 C. pectinata. M: Manzanillo, N: Las Negras, Z: Zapotitlán de las Salinas. Numbers 1-3 show

798 site locations mentioned in the main text where new mtDNA haplotypes were uncovered. Map

799 was generated with Google Earth (Data LDEO - Columbia, NSF, NOAA, Image Landsat /

800 Copernicus. Imagery date 12/13/2015).

801

802 Figure 2. Phylogenetic tree and population assignment results. (A) Suggested taxonomic

803 changes in relation to mtDNA and nuclear data analyses; (B) Phylogenetic tree calculated with

804 mtDNA sequences showing the clades proposed by Zarza, Reynoso \& Emerson (2008); (C)

805 mtDNA lineage of each individual as defined in haplotype networks calculated by Zarza,

806 Reynoso \& Emerson (2008, 2011); (D) microsatellite genotypic cluster defined with

807 STRUCTURE under K=4; (E) substructure estimated with STRUCTURE in a reduced data set

808 (South-SS analyses). In STRUCTURE plots, the Y-axis represents proportion of ancestry. Each

809 bar represents an individual. White bars are missing data.

810

811 Tables 
812 Table 1. Sources of variation for mtDNA and microsatellite data calculated with SAMOVA

813 under $\mathbf{K}=\mathbf{1 0}$ and $\mathbf{K}=\mathbf{5}$ respectively. Bold font indicates statistically significant values $(\mathrm{p}<0.05)$.

814

815 Table 2. Summary statistics per locus for genotypic clusters (*Nuc 1-*Nuc 5) defined with 816 SAMOVA.

817

818 Table 3. Differentiation between SAMOVA clusters ( $\boldsymbol{F}_{\boldsymbol{S} T}$ values) as estimated with Arlequin

819 3.5. All values are statistically significant $(\mathrm{p}<0.05)$.

820

821 Table 4. Number of individuals assigned to each hybrid class according to NewHybrids. In 822 all cases, SAMOVA defined clusters were compared.

823

824 Supplemental information

825 Figure S1. MtDNA haplotype network. Calculated with data from Zarza, Reynoso \& Emerson 826 (2008, 2011); Haplotypes produced by Zarza Franco (2008) were added to the North A lineage 827 and are highlighted with a red circle.

828

829 Figure S2. Bar plots showing population assignment and ancestry for individuals according 830 to different methods. (A) MtDNA lineage of each individual as defined in haplotype networks 831 calculated by Zarza, Reynoso \& Emerson (2008, 2011); (B) SAMOVA mtDNA groups detected 832 under $\mathrm{K}=10$; (C) microsatellite genotypic cluster defined with SAMOVA under $\mathrm{K}=5$ and (D) 833 STRUCTURE under K=4; (E) substructure estimated with STRUCTURE in a reduced data set 834 (South-SS analyses). In STRUCTURE plots, the Y-axis represents proportion of ancestry. As 
835 this cannot be calculated with SAMOVA, values are always shown as 1. Each bar represents an

836 individual. White bars are missing data.

837

838 Figure S3. A male spiny-tailed iguana from Sinaloa, northern Mexico, with the

839 characteristic yellow coloration. Here we propose that populations from northern Mexico are

840 referred as Ctenosaura brachylopha. Photo Credit: Eugenia Zarza.

841

842 File S1. Sampling localities, geographic coordinates, haplotype accession numbers and

843 genotype data of individuals included in this study, and summary of previous research

844 outcomes.

845

846 File S2. SAMOVA K associated FCT values, $\triangle$ FCT plots; STRUCTURE K likelihoods and

$847 \Delta$ K plots.

848

849 Table S1. $\boldsymbol{F}_{\boldsymbol{S T}}$ values between pairs of localities estimated with Arlequin 3.5.

850 


\section{Figure 1}

Geographic distribution of mtDNA lineages and genotypic clusters within Ctenosaura pectinata and C. acanthura.

Lines represent the geographical limits of the mtDNA lineages. Colors and lineage names follow the scheme shown in the haplotype network (Fig. S1). Pie charts show proportion of ancestry among individuals sampled in each locality with colors equivalent to STRUCTURE clusters. A: Apatzingán, $\mathrm{H}$ : contact zone between $\mathrm{C}$. hemilopha and $\mathrm{C}$. pectinata. $\mathrm{M}$ : Manzanillo, N: Las Negras, Z: Zapotitlán de las Salinas. Numbers 1-3 show site locations mentioned in the main text where new mtDNA haplotypes were uncovered. Map was generated with Google Earth (Data LDEO - Columbia, NSF, NOAA, Image Landsat / Copernicus. Imagery date 12/13/2015). 


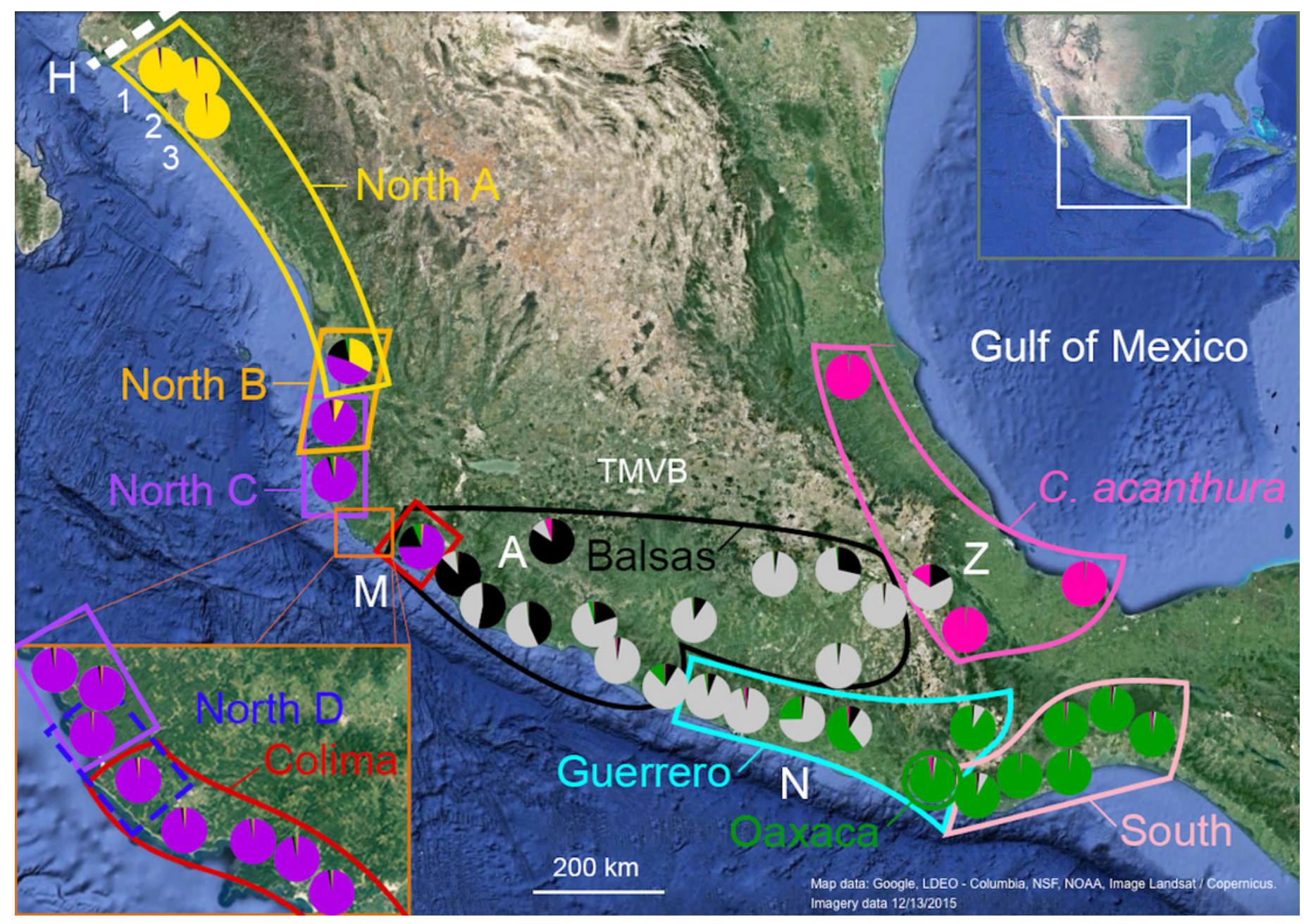


Figure 2 (on next page)

Phylogenetic tree and population assignment results.

(A) Suggested taxonomic changes in relation to mtDNA and nuclear data analyses; (B) Phylogenetic tree calculated with mtDNA sequences showing the clades proposed by Zarza, Reynoso \& Emerson (2008); (C) mtDNA lineage of each individual as defined in haplotype networks calculated by Zarza, Reynoso \& Emerson (2008, 2011); (D) microsatellite genotypic cluster defined with STRUCTURE under $K=4$; (E) substructure estimated with STRUCTURE in a reduced data set (South-SS analyses). In STRUCTURE plots, the Y-axis represents proportion of ancestry. Each bar represents an individual. White bars are missing data. 
$\mathrm{r}$
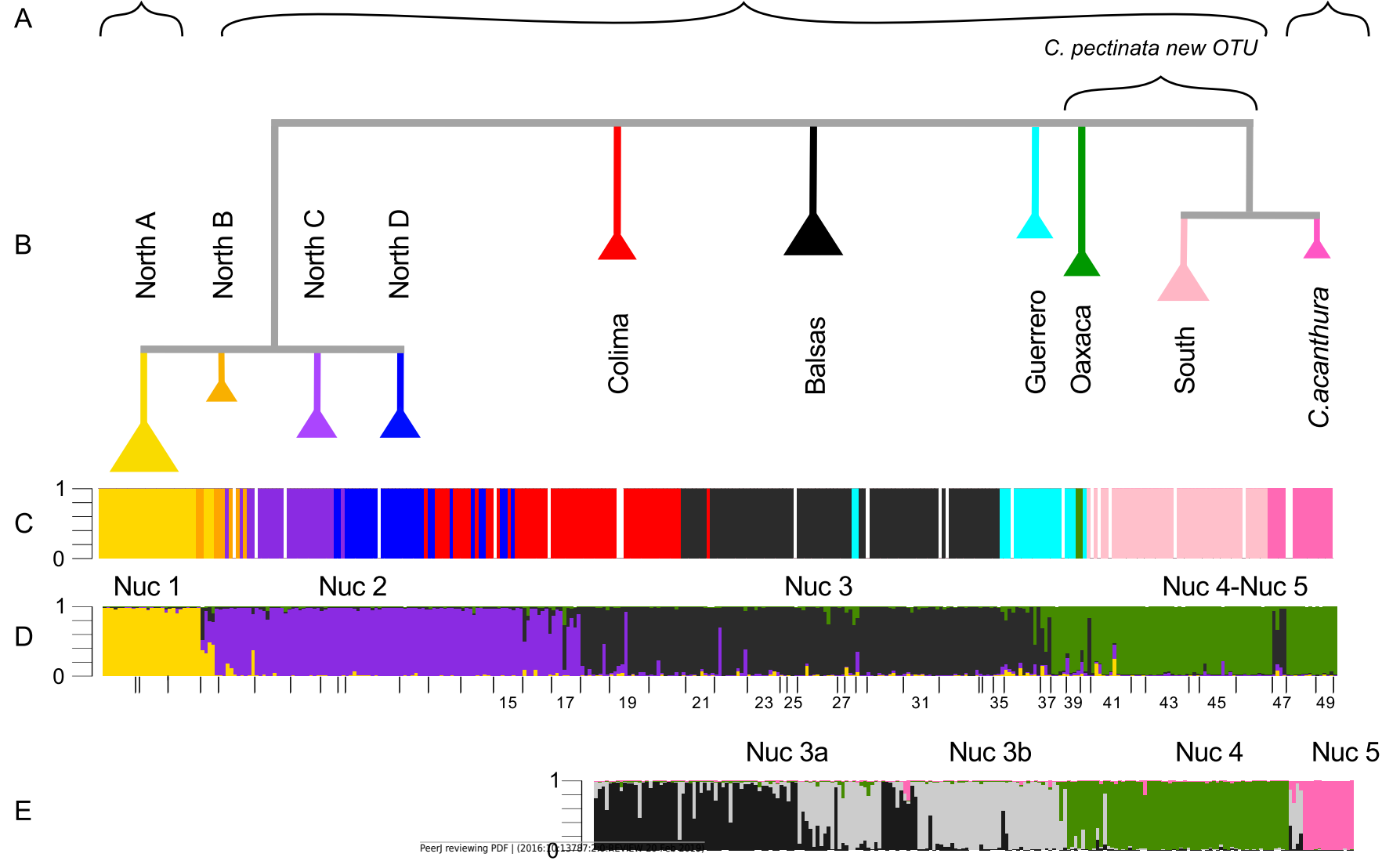


\section{Table $\mathbf{1}$ (on next page)}

Sources of variation for mtDNA and microsatellite data calculated with SAMOVA under $\mathrm{K}=10$ and $\mathrm{K}=5$ respectively.

Bold font indicates statistically significant values $(p<0.05)$. 
1 Table 1. Sources of variation for mtDNA and microsatellite data calculated with SAMOVA

2 under $K=\mathbf{1 0}$ and $K=5$ respectively. Bold font indicates statistically significant values ( $p<0.05)$.

\begin{tabular}{|c|c|c|c|c|c|c|}
\hline Marker & $\begin{array}{l}\text { Source of } \\
\text { variation }\end{array}$ & d.f. & $\begin{array}{l}\text { Sum of } \\
\text { squares }\end{array}$ & $\begin{array}{c}\text { Variance } \\
\text { components }\end{array}$ & $\begin{array}{c}\% \\
\text { variation } \\
\end{array}$ & $\begin{array}{l}\text { Fixation } \\
\text { indices }\end{array}$ \\
\hline \multirow{4}{*}{ mtDNA } & $\begin{array}{l}\text { Among } \\
\text { groups }\end{array}$ & 9 & 3061.309 & 9.779 & 79.28 & $F_{C T}=0.793$ \\
\hline & $\begin{array}{c}\text { Among } \\
\text { populations } \\
\text { within groups }\end{array}$ & 43 & 332.944 & 1.002 & 8.12 & $F_{S C}=0.392$ \\
\hline & $\begin{array}{c}\text { Within } \\
\text { populations }\end{array}$ & 291 & 452.013 & 1.553 & 12.59 & $F_{S T}=0.874$ \\
\hline & Total & 343 & 3846.266 & 12.334 & & \\
\hline \multirow{5}{*}{$\begin{array}{l}\text { microsate } \\
\text { llites }\end{array}$} & $\begin{array}{l}\text { Among } \\
\text { groups }\end{array}$ & 4 & 268.732 & 0.517 & 21.66 & $F_{C T}=0.217$ \\
\hline & $\begin{array}{c}\text { Among } \\
\text { populations } \\
\text { within groups }\end{array}$ & 44 & 164.372 & 0.145 & 6.08 & $F_{S C}=0.078$ \\
\hline & $\begin{array}{c}\text { Among } \\
\text { individuals } \\
\text { within } \\
\text { populations }\end{array}$ & 292 & 513.913 & 0.034 & 1.42 & $F_{I S}=0.02$ \\
\hline & $\begin{array}{c}\text { Within } \\
\text { individuals }\end{array}$ & 341 & 577 & 1.692 & 70.84 & $F_{I T}=0.292$ \\
\hline & Total & 681 & 1524.018 & 2.389 & & \\
\hline
\end{tabular}

3 
Table 2 (on next page)

Summary statistics per locus for genotypic clusters (*Nuc 1-*Nuc 5) defined with SAMOVA. 
Table 2. Summary statistics per locus for genotypic clusters (*Nuc 1-*Nuc 5) defined with SAMOVA. 3

\begin{tabular}{|c|c|c|c|c|c|c|c|c|c|c|c|c|c|c|c|c|c|c|c|c|}
\hline & \multicolumn{4}{|c|}{ *Nuc 1} & \multicolumn{4}{|c|}{ *Nuc 2} & \multicolumn{4}{|c|}{ *Nuc 3} & \multicolumn{4}{|c|}{ *Nuc 4} & \multicolumn{4}{|c|}{ *Nuc 5} \\
\hline $\mathbf{L}$ & $\mathbf{A}$ & $\mathbf{H}_{\mathbf{O}}$ & $\mathbf{H}_{\mathrm{E}}$ & $F_{I S}$ & A & $\mathbf{H}_{\mathbf{O}}$ & $\mathbf{H}_{\mathrm{E}}$ & $F_{I S}$ & A & $\mathbf{H}_{\mathbf{O}}$ & $\mathbf{H}_{\mathbf{E}}$ & $F_{I S}$ & $\mathbf{A}$ & $\mathbf{H}_{\mathbf{O}}$ & $\mathbf{H}_{\mathbf{E}}$ & $F_{I S}$ & $\mathbf{A}$ & $\mathbf{H}_{\mathbf{O}}$ & $\mathbf{H}_{\mathbf{E}}$ & $F_{I S}$ \\
\hline 1 & 4 & 0.48 & 0.49 & 0.01 & 13 & 0.86 & 0.86 & 0.00 & 12 & 0.79 & 0.82 & 0.05 & 14. & 0.68 & 0.84 & 0.19 & 3 & 0.14 & 0.52 & 0.73 \\
\hline 2 & 2 & 0.41 & 0.50 & 0.19 & 6 & 0.33 & 0.35 & 0.05 & 7 & 0.44 & 0.45 & 0.01 & 6 & 0.36 & 0.49 & 0.27 & 4 & 0.14 & 0.51 & 0.72 \\
\hline 3 & 8 & 0.85 & 0.80 & -0.06 & 15 & 0.78 & 0.85 & 0.08 & 25 & 0.83 & 0.91 & 0.09 & 13 & 0.54 & 0.79 & 0.32 & 5 & 0.64 & 0.75 & 0.15 \\
\hline 4 & 2 & 0.52 & 0.50 & -0.03 & 7 & 0.45 & 0.45 & 0.00 & 8 & 0.74 & 0.80 & 0.07 & 5 & 0.14 & 0.16 & 0.14 & 3 & 0.64 & 0.63 & -0.02 \\
\hline 5 & 3 & 0.78 & 0.68 & -0.15 & 7 & 0.51 & 0.55 & 0.06 & 6 & 0.25 & 0.28 & 0.10 & 5 & 0.63 & 0.71 & 0.13 & 2 & 0.07 & 0.07 & 0.00 \\
\hline 6 & 3 & 0.15 & 0.14 & -0.05 & 11 & 0.77 & 0.84 & 0.09 & 10 & 0.50 & 0.66 & 0.25 & 11 & 0.72 & 0.84 & 0.14 & 2 & 0.29 & 0.48 & 0.41 \\
\hline 7 & 6 & 0.59 & 0.62 & N.A. & 10 & 0.63 & 0.74 & N.A. & 14 & 0.55 & 0.74 & N.A. & 4 & 0.07 & 0.58 & 0.10 & $\mathrm{~m}$ & $\mathrm{~m}$ & $\mathrm{~m}$ & N.A. \\
\hline 8 & 8 & 0.67 & 0.82 & 0.19 & 13 & 0.77 & 0.80 & 0.04 & 13 & 0.83 & 0.86 & 0.03 & 8 & 0.67 & 0.74 & & $\mathrm{~m}$ & $\mathrm{~m}$ & $\mathrm{~m}$ & N.A. \\
\hline $\mathbf{M}$ & 4.5 & 0.56 & 0.57 & & 10.3 & 0.64 & 0.68 & & 11.9 & 0.62 & 0.69 & & 8.3 & 0.48 & 0.65 & & 3.2 & 0.32 & 0.49 & \\
\hline s.d. & 2.5 & 0.22 & 0.22 & & 3.3 & 0.19 & 0.20 & & 6.0 & 0.21 & 0.22 & & 3.9 & 0.26 & 0.23 & & 1.2 & 0.26 & 0.23 & \\
\hline $\mathbf{n}$ & \multicolumn{4}{|c|}{27} & \multicolumn{4}{|c|}{105} & \multicolumn{4}{|c|}{131} & \multicolumn{4}{|c|}{64} & \multicolumn{4}{|c|}{14} \\
\hline $\mathbf{A R}$ & \multicolumn{4}{|c|}{$3.29(2.64)$} & \multicolumn{4}{|c|}{$5.14(3.98)$} & \multicolumn{4}{|c|}{$5.54(4.65)$} & \multicolumn{4}{|c|}{$4.7(3.19)$} & \multicolumn{4}{|c|}{$2.56(1.38)$} \\
\hline PA & \multicolumn{4}{|c|}{$0.29(0.07)$} & \multicolumn{4}{|c|}{$0.62(0.18)$} & \multicolumn{4}{|c|}{$0.96(0.60)$} & \multicolumn{4}{|c|}{$0.76(0.40)$} & \multicolumn{4}{|c|}{$0.53(0.29)$} \\
\hline $\mathrm{Ne}$ & \multicolumn{4}{|c|}{$35.1(0-176)$} & \multicolumn{4}{|c|}{$8.5(1.8-20.5)$} & \multicolumn{4}{|c|}{$15.8(5.8-30.8)$} & \multicolumn{4}{|c|}{$22.5(0-112.8)$} & \multicolumn{4}{|c|}{$1.9(1.3-2.7)$} \\
\hline
\end{tabular}

4

$5 \mathrm{~L}=$ Locus; $\mathrm{A}=$ Allele number; $\mathrm{H}_{\mathrm{O}}=$ Observed heterozygosity; $\mathrm{H}_{\mathrm{E}}=$ Expected heterozygosity; FIS = inbreeding coefficient; $\mathrm{N} . \mathrm{A} .=$ 6 missing data; $\mathrm{m}=$ monomorphic locus; $\mathrm{n}=$ number of individuals; $\mathrm{M}=$ Mean; $\mathrm{s.d}$. = standard deviation; $\mathrm{AR}=\mathrm{Allele}$ richness; $\mathrm{PA}=$ 7 Private alleles mean (variance); $\mathrm{Ne}=$ Effective population size (Jackknife CI) 


\section{Table 3 (on next page)}

Differentiation between SAMOVA clusters ( $F_{S T}$ values) estimated with Arlequin 3.5. All values are statistically significant $(p<0.05)$. 
Arlequin 3.5. All values are statistically significant $(\mathrm{p}<0.05)$.

\begin{tabular}{|l|r|r|r|r|}
\hline & \multicolumn{1}{|l|}{ *Nuc 1 } & *Nuc 2 & *Nuc 3 & *Nuc 4 \\
\hline *Nuc 1 & 0 & & & \\
\hline *Nuc 2 & 0.18952 & 0 & & \\
\hline *Nuc 3 & 0.26536 & 0.14815 & 0 & \\
\hline *Nuc 4 & 0.28768 & 0.18468 & 0.15797 & 0 \\
\hline *Nuc 5 & 0.44634 & 0.36999 & 0.32849 & 0.34052 \\
\hline
\end{tabular}

3 


\section{Table 4 (on next page)}

Number of individuals assigned to each hybrid class according to NewHybrids. In all cases, SAMOVA defined clusters were compared. 
1 Table 4. Number of individuals assigned to each hybrid class according to NewHybrids. In 2 all cases, SAMOVA defined clusters were compared.

\begin{tabular}{|c|c|c|c|c|c|c|c|c|}
\hline X,Y & $\begin{array}{c}\text { Pure } \\
\text { *Nuc X }\end{array}$ & $\begin{array}{c}\text { Pure } \\
\text { *Nuc Y }\end{array}$ & F1 & F2 & $\begin{array}{c}\text { *Nuc X } \\
\text { Bc. }\end{array}$ & $\begin{array}{c}\text { *Nuc Y } \\
\text { Bc. }\end{array}$ & $\begin{array}{c}\text { Un- } \\
\text { assigned }\end{array}$ & $\begin{array}{c}\mathbf{n} \\
(\mathbf{X + Y})\end{array}$ \\
\hline *Nuc 1,*Nuc 2 & 26 & 92 & 0 & 1 & 0 & 0 & 13 & 132 \\
\hline *Nuc 2,*Nuc 3 & 83 & 0 & 0 & 37 & 0 & 4 & 112 & 236 \\
\hline *Nuc 3,*Nuc 4 & 110 & 56 & 0 & 0 & 2 & 0 & 27 & 195 \\
\hline *Nuc 3,*Nuc 5 & 125 & 14 & 0 & 2 & 0 & 0 & 4 & 145 \\
\hline *Nuc 4,*Nuc 5 & 14 & 64 & 0 & 0 & 0 & 0 & 0 & 78 \\
\hline
\end{tabular}

$3 \mathrm{X}, \mathrm{Y}=\mathrm{SAMOVA}$-defined Genotypic cluster compared. As in the main text, tables and figures,

4 the *Nuc prefix denotes SAMOVA defined genotypic cluster. $\mathrm{Bc}=$ backcross 